\title{
Assessment of Vestibular and Oculomotor Function in Patients with Vestibular Migraine: A Preliminary Study
}

\section{Wei Fu}

Xijing Hospital

Junliang Han

Xijing Hospital

Feng He

Xijing Hospital

\section{Ya Bai}

Xijing Hospital

\section{Dong Wei}

Xijing Hospital

\section{Ning Chang}

Xijing Hospital

\section{Ying Shi}

Xijing Hospital

\section{Yuanyuan Wang ( $\square$ xijingvertigo@126.com )}

Xijing Hospital https://orcid.org/0000-0003-3594-8785

\section{Research article}

Keywords: Vestibular migraine, Vestibular function, Oculomotor, Vestibular-evoked myogenic potentials, Video head impulse test, Caloric irrigation test, Videonystagmography, Prophylaxis,Medications

Posted Date: June 8th, 2020

DOI: https://doi.org/10.21203/rs.3.rs-31023/v1

License: (c) (i) This work is licensed under a Creative Commons Attribution 4.0 International License. Read Full License 


\section{Abstract}

Background: The purpose of the study is to assess the vestibular and oculomotor function in patients with vestibular migraine(VM).And we also investigate the relationship between test resultsandeffectiveness of prophylactic medication.

Methods: We recruited 41 patientswith VM. They were examinedwith vestibular-evoked myogenic potentials(VEMP), video head impulse test(vHIT) and videonystagmography(VNG), including spontaneous or positional nystagmus, gaze-evoked nystagmus, smooth pursuit and caloric irrigation testing.All VM patients were treated withprophylactic medications. Theintensity of vertigo were evaluated with dizziness handicap inventory $(\mathrm{DHI})$ before and after treatment. After 6 months, we evaluate the effectiveness of prophylactic medication. We analyzed the relationship between test resultsandeffectiveness of prophylactic medication.

Results:In vestibular function test,71\% of VM patients showed abnormal result. $20 \%$ showed abnormal air-conducted cVEMP and $42 \%$ showed abnormal air-conducted oVEMP. $32 \%$ showed abnormal VHIT and $56 \%$ showed abnormal caloric irrigation test. The abnormal rate of oVEMP was significantly higher than cVEMP $(p<0.05)$. And the abnormal rate of caloric irrigation test was significantly higher than $\operatorname{vHIT}(p<0.05)$. In oculomotor function test, $42 \%$ showed pathological result. The abnormal rate of oculomotor function test was significantly lower than vestibular function test $(p<0.05)$. After 6 months follow-up, rate of good effectiveness was significantly higher in normal vestibular function test group compared with the abnormal vestibular function test group $(p<0.05)$. Rate of good effectiveness was no statistically significant difference between normal oculomotor function test group and abnormal oculomotor function test group ( $p>0.05)$.

Conclusions: Abnormal vestibular and oculomotor function are commonly observed in VM patients. And VM patients with abnormal vestibular function have a weak effectiveness of prophylaxis medications.

\section{Background}

Vestibular migraine (VM) is a common cause of attacks of episodic vertigo[1].It can accounts for $7 \%$ of patients seen in dizziness clinics and $9 \%$ of patients seen in headache clinics[1]. Although the committee of the bárány society and a subcommitteeof the international headache society (IHS)have developed a clearercriteria for VM[2, 3]. Diagnosis of vestibular migraine is challenging. Since the criteria for VMis based on clinical manifestations. And symptoms associated with vestibular migraine arevaried. It is difficulty that clinical diagnosis competely fulfill thediagnostic criteria of VM. And the pathophysiology of VM is not uncertain. Some studies reported that it was likely of a central nervous system origin[4, 5].0ther studies considered that peripheral vestibular was probably involved[6].Therefore,clinical tests, such as vestibular function and oculomotor function test, would be helpfulon VM understanding.

During the last decade, vestibular function test has evolved such that the semicircularcanalsandtheotolithsystem[7]. Vestibular-evoked myogenic potentials(VEMP) is a useful 
method forevaluating function from the otolithsystem[8]. And video head impulse test(vHIT) evaluates the semicircularcanal function in response tohigh-frequency headmovements and caloric irrigation test, and low-frequency head movements[9].Recording and measurement of oculomotoris performedwith videonystagmography(VNG)[7]. These testshave providedclinicians with useful diagnostic tools to identifydysfunctions of different vestibular pathways. However,there is not adequate assessment in VM patients.

In this study, we assess the vestibular and oculomotor function in patients with VM.And we also investigate the relationship between test result andeffectiveness of prophylactic medication.

\section{Methods}

\section{Participants}

We recruited 41 patients with VM from the period between 2017 and 2019 (26 females, 15 males; mean age 49.3 years; range 19-76 years). They were diagnosed to VM according to the criteria of thecommittee of the báránysociety and a subcommittee of the IHS[2, 3].All patients were assessed using VEMP, vHIT and VNG(including spontaneous or positional nystagmus, gaze-evoked nystagmus, smooth pursuit, saccade test and caloric irrigation test). And all VM patients were treated withprophylactic medications. After 6 months, we evaluate the effectiveness of prophylactic medication.All VM patients were inquired the intensity of vertigo and completed the chinese version of the dizziness handicap inventory (DHI) questionnaire before and after treatment. And VM patients were then classified as good effectiveness (symptomatic improvement $\geq 50 \%$ ), partial effectiveness ( $30 \% \leq$ symptomatic improvement $₫ 50 \%$ ) and poor effectiveness(symptomatic improvement $₫ 30 \%$ ).

\section{VEMP}

VEMP recordings were performed with a evoked potential instrument (GN Otometrics EP200; version 6.2.1). $500 \mathrm{~Hz}$ air-conducted tone bursts were presented monaurally via a pair of calibrated insert earphones at an intensity of $100 \mathrm{~dB} \mathrm{nHL}$. We used the following stimulus profile: $2 \mathrm{~ms}$ rise time, $2 \mathrm{~ms}$ plateau time and $2 \mathrm{~ms}$ fall time. The stimulation rate was $5 / \mathrm{s}$, with the analysis time for each response of $60 \mathrm{~ms}$, and 100 repetitions per trial were delivered.The EMG signals were amplified and bandpass-filtered between 1 and $1000 \mathrm{~Hz}$.In cVEMP, after the patients were laid supine,an active electrode was placed on the upper third of the sternocleidomastoidmuscle. The forehead served asthe site for the ground electrode. The electrode impedance was kept under $5 \mathrm{k} \Omega$. During recording, patients were asked to elevate theirheads. In oVEMP, an active electrode was placed on the face just inferior to each eye, around $1 \mathrm{~cm}$ below the center of the lower eyelid. The reference electrode was positioned on the cheek, about $1-2 \mathrm{~cm}$ below the corresponding active electrode, and the ground electrode was placed on the forehead. The electrode impedance was kept under $5 \mathrm{k} \Omega$. During recording, the subject was instructed to look upward at a small fixed point approximately $30^{\circ}$ at a distance of approximately $60 \mathrm{~cm}$ from the eyes. And the biphasic waveform were performed to confirm the reproducibility at least 3 times. Peak-to-peak amplitudeswere calculated from the mean value of the replicate waveforms for each condition. The 
asymmetry ratio $(A R)=($ Left amplitude-Right amplitude $) /($ Left amplitude + Right amplitude $) \times 100$. In cVEMP, abnormal criteria is the AR $>20 \%$.And in oVEMP, abnormal criteria is the AR $>30 \%[10]$.

\section{vHIT}

The VHIT was recordedusing the ICS Impulsesystem (Otometrics, Denmark). All horizontal and vertical canals wereevaluated. The subject was instructed to gaze at a target thatwas $1.2 \mathrm{~m}$ away. First, calibration is performed. In each trial,the examiner stood behind the patients and performed headimpulses by a small angle (10-20。) and an appropriatevelocity (150-200。/s). And 20 impulses were recorded for eachdirection. The lowest and highest valuesof the normal gain were 0.8 and 1.2 at horizontalvHIT and 0.63 and 1.15 at vertical VHIT. Besides, a corrective saccades peak velocity > 100\%/swas considered pathologic[11-13].

\section{Videonystagmography}

Videonystagmography was performed using the Chart 200 VEG/ENG system (Otometrics, Denmark). Calibration with the patient seated was done as the first step. Oculomotor test battery including spontaneous or positional nystagmus, gaze-evoked nystagmus, smooth pursuit, saccade test and caloric irrigation test.The bithermal air caloric irrigations were performed with the patient in the supine position. Each ear were irrigated witha airflow of $8 \mathrm{~L} / \mathrm{min}$ at $50^{\circ} \mathrm{C}$ and $24^{\circ} \mathrm{C}$ for seconds. Unilateral weakness(UW) making was based on Jongkee's formula. Abnormal criteria is the UW values $₫ 25 \%[14]$.

\section{Statistical Analysis}

Chi-square or Fisher exact test was used to compare rate of abnormal vestibular and oculomotortests.Statistical comparisons of symptomatic improvement in different test groups were made using the Chi-square or Fisher exact. $p<0.05$ was consideredstatistically significant. Statistical analysis were done by usingSPSS software (version19, SPSS Inc., Chicago, IL, USA).

\section{Results}

\section{Clinical characteristics of patients with vestibular migraine}

Among the41VM patients, 24(59\%) patients showedspontaneous vertigo, 7(17\%) had positional vertigo, $5(12 \%)$ had head motion-induced vertigo, and $5(12 \%)$ had unsteadiness. In most patients, severity of vestibular symptom was moderate to severe(DHI score $>30)$. Vestibular symptoms lasted lessthan 1 minute in $1(2 \%)$ patients, 1 minute to less than 1 hour in $16(39 \%)$ patients, 1 hour to less than 24 hours in $21(51 \%)$ patients, and more than 24 hours in $3(7 \%)$ patients. One or more migraine features with at least $50 \%$ ofthe vestibular episodes such asone sided location $32(78 \%)$, pulsating quality $23(56 \%)$, moderate or severe pain intensity $28(68 \%)$, aggravation by routine physical activity $17(42 \%)$, photophobia $16(39 \%)$, phonophobia $18(44 \%)$ or visual aura $7(17 \%)$. Tinnitus and hearing loss were reportedin $20(49 \%)$ and 16(39\%) patients, respectively. The characteristics of VM patients are summarized inTable 1.

\section{Vestibular and oculomotor function in VM patients}


In vestibular function test, 29(71\%) VM patients showed abnormal result.8(20\%) showed abnormal airconducted cVEMP and 17(42\%) had abnormal air-conducted oVEMP. In vHIT, Abnormal results were observed in 13(32\%).Abnormal horizontal canal VHIT were recorded in 6(15\%) patients and abnormal vertical canal VHIT were recorded in 11(27\%) patients. In caloric irrigation test,23(56\%) exhibited abnormal UW. The abnormal rate of oVEMP was significantly higher than $\operatorname{CVEMP~}(p<0.05$,Fig. 1$)$. And the abnormal rate of caloric irrigation test wassignificantly higher than $\operatorname{vHIT}(p \llbracket 0.05, \mathrm{Fig} .1)$.

In oculomotor function test, 17(42\%) VM patients showed pathological result such as 4(10\%) with spontaneous nystagmus, $10(24 \%)$ with positional nystagmus, $1(2 \%)$ with gaze-evoked nystagmus, and $7(17 \%)$ with smooth pursuit. The abnormal rate of oculomotor function test were significantly lower than vestibular function test ( $p \otimes 0.05)$.

\section{Symptomatic improvement in VM patients at the follow-up}

After 6 months follow-up, 21(51\%) VM patients reported a good effectiveness in their symptoms and $17(42 \%)$ reported a partial effectiveness in their symptoms while $3(7 \%)$ experienced poor effectiveness. Rate of good effectiveness was significantly higher in normal vestibular function test group compared with the abnormal vestibular function test group ( $<<0.05$, Table 2, Fig. 2). Rate of good effectiveness was no statistically significant difference between normal oculomotor function test group and abnormal oculomotor function test group $(p>0.05$, Table 3, Fig. 3). 
Table 1

The clinical characteristics of VM patients $(n=41)$.

\begin{tabular}{|ll|}
\hline Type & $\mathrm{n}(\%)$ \\
\hline Vestibular symptoms & \\
\hline Spontaneous vertigo & $24(59)$ \\
\hline Positional vertigo & $7(17)$ \\
\hline Head motion-induced vertigo & $5(12)$ \\
\hline Unsteadiness & $5(12)$ \\
\hline Severity of vestibular symptom & \\
\hline Mild(DHI 30$)$ & $7(17)$ \\
\hline Moderate to severe(DHI > 30) & $34(83)$ \\
\hline Duration of episodes & \\
\hline Lasting seconds & $1(3)$ \\
\hline Lasting minutes & $16(39)$ \\
\hline Lasting hours & $21(51)$ \\
\hline Lasting days & $3(7)$ \\
\hline Migraine featuresofthe vestibular episodes & \\
\hline one sided location & $32(78)$ \\
\hline pulsatingquality & $23(56)$ \\
\hline moderate or severe pain intensity & $28(68)$ \\
\hline aggravation byroutine physical activity & $17(42)$ \\
\hline photophobia & $16(39)$ \\
\hline phonophobia & $18(44)$ \\
\hline visual aura & $7(17)$ \\
\hline Auditory symptoms & \\
\hline Tinnitus & $20(49)$ \\
\hline Hearing loss & \\
\hline
\end{tabular}


Table 2

Effectiveness of prophylaxis medications in different vestibular test group.

\begin{tabular}{|lllll|}
\hline & n & $\begin{array}{l}\text { good } \\
\text { effectiveness(\%) }\end{array}$ & $\begin{array}{l}\text { partial } \\
\text { effectiveness(\%) }\end{array}$ & $\begin{array}{l}\text { poor } \\
\text { effectiveness(\%) }\end{array}$ \\
\hline Vestibular normal group & 12 & $10(83)$ & $2(17)$ & 0 \\
\hline $\begin{array}{l}\text { Vestibular abnormal } \\
\text { group }\end{array}$ & 29 & $11(38)$ & $15(52)$ & $3(10)$ \\
\hline
\end{tabular}

Table 3

Effectiveness of prophylaxis medications in different oculomotor test group.

\begin{tabular}{|lllll|}
\hline & n & $\begin{array}{l}\text { good } \\
\text { effectiveness(\%) }\end{array}$ & $\begin{array}{l}\text { partial } \\
\text { effectiveness(\%) }\end{array}$ & $\begin{array}{l}\text { poor } \\
\text { effectiveness(\%) }\end{array}$ \\
\hline $\begin{array}{l}\text { Oculomotor normal } \\
\text { group }\end{array}$ & 24 & $14(58)$ & $8(34)$ & $2(8)$ \\
\hline $\begin{array}{l}\text { Oculomotor abnormal } \\
\text { group }\end{array}$ & 17 & $7(41)$ & $9(53)$ & $1(6)$ \\
\hline
\end{tabular}

\section{Discussion}

VM is a distinct clinical entity that accounts for a high proportion of vestibular symptoms.Diagnosis of VM mainly dependson recurrent vestibular symptoms, ahistory of migraine, a temporal association between vestibular symptoms and migraine symptoms and exclusion of other reasons[2].And vestibular symptoms is based on the bárány society's classification of vestibular symptoms such as spontaneous vertigo, positional vertigo, visually-induced vertigo,head motion-induced vertigo and head motion-induced dizziness with nausea[15].In our studies, more than half of VM patientsare found spontaneous vertigo.10-20\%VM patients have other forms of vertigo. We can find thatthe most common vestibular symptom is spontaneous vertigo.Findings of most of studiesare similar our results $[1,16,17]$. Although most of VM patients have moderate to severevestibular symptoms. We still found some mild VM patients. This may be due todifferent measurements. In VM diagnostic criteria,vestibular symptoms are rated "moderate" whenthey interfere with but do not prohibit daily activities and "severe" if daily activities cannot becontinued[2].However, in our studies, vestibular symptoms is assess with DHI.In VM, duration of episodes have been reported at varying lengths, rangingfrom seconds to days and most often between minutes to hours[18].In our study, most VM patients were reported lasting minutes to hours. Thisis consistent with the previous literature[18].Besides,different migraine features may occur duringvestibular episodes, including unilaterality, pulsating quality, moderateto severe intensity,worsening with physical activity, photophobia, phonophobia and visual aura.In our study,the visual aura is infrequent in VM patients.Furman et al.reported thatVM is more common in patients without aura than in patients with aura[19].The view support our study result. We also found thatauditory symptoms is like tinnitus and hearing loss have been foundin $49 \%$ and $39 \%$ of VM patients. It is reported thatthe number of patients 
with auditory symptoms will be more than doubles as the progression of VM[20]. However, hearing loss does not progress to profoundlevels[21].

VM is classified entirely on the basisof clinical features as reported by the patient[21].However, VM patients can also find abnormal results in vestibular and oculomotor function test.In our study,most of VM patients have abnormal vestibular function test.It includes otolithfunction(VEMP) and semicircular canalfunction(VHITand caloric irrigation test).In VEMP,we found that oVEMP has a higher abnormal rate. After testing 39VM patients with cVEMP and oVEMP, Zaleski et al.reported that oVEMP may be especially vulnerable in patients with VM[22]. This is consistent with our result.In semicircularcanalsystem,VHIT evaluated the semicircularcanal function in response tohigh-frequency head rotationand caloric irrigation test, and low-frequency head rotation[9]. According to our study result,the abnormal rateof caloric irrigation test was higher than vHIT.It suggests that low-frequencysemicircularcanal function is vulnerablein VM patients.And the results in our studyis also in accordance with the previous reports[23, 24].Apart from vestibular function, oculomotorfunction is also a important sign in VM.In the symptomfree interval, nearly half of VM patientswere found abnormal oculomotor tests in our study. Such signsinclude spontaneous nystagmus, positional nystagmus, gaze-evoked nystagmus and smooth pursuit.In previous reports,oculomotorabnormalities were reported in 8 to $60 \%$ of VM patients[6,25-27]. There is a wide incidence of oculomotorabnormalities.It may be relate to course of disease. Incidence rate of oculomotorabnormalities can increase over time[20].Besides,oculomotorabnormalities is especially common during attacks of VM[18]. In addition, we furtherfound thatpositional nystagmus and smooth pursuit are common in oculomotorabnormalities. It similar to previous studies[20,28]. These results related to mechanisms of VM. Apart from central mechanisms an inner ear involvement may explain abnormal findings. Trigeminovascularreflex-mediated vasodilatation of cranial blood vessels andsubsequently plasma extravasation causing meningealinflammation are the key reasonand trigeminovascular system also innervates the inner ear $[1,19]$.

Medications used for migraine prophylaxis can be used totreat VM[18].In our study,we found that half of VM patientsreported good effectivenes in their symptoms through prophylactic medications after 6 monthsfollow-up.However, there are still nearly half of VM patients that requiring medication continued or medication change(partial or poor effectiveness). How to identify the possible influencing factors before preventative medications in VM. Therefore, according to vestibular and oculomotor test results, wedivided them into different subgroups.Compared with abnormal vestibular function group, we found that most of VM patients with normal vestibular function group were good effectiveness.It suggest that vestibular function abnormalities are closely related to the effectiveness of prophylaxis medication of VM.However,the effectiveness of prophylaxis medication was no significant difference between normal and abnormal oculomotor function test in VM patients. Kang et al.found that abnormal results of VHIT and caloric tests were closely related to the necessity for continued medication in VM patientsat 6-month follow-up[29]. Besides, Jung et al.also report that there was a good drug responsiveness in VM patients with normal VEMP[30]. These results were similar to ourstudy. It was proved that there is a weak effectiveness of prophylaxis medications in VM patients with abnormalvestibular function. But the 
specific mechanism is not clear. Future basic studies are promising in the prophylaxis medicationmechanisms of VM.

\section{Limitations}

There are some limitations in this study. First, the number of VM patients and follow-up time were insufficient. The future studywith a large samples and longer follow-up time need to furtherconfirm our results. Second, different prophylaxis medications or a combination of multiplemedications requires further evaluation. Last, future studies need to investigate the role of specific parameters in vestibular and oculomotor function tests.

\section{Conclusion}

Abnormal vestibular and oculomotorfunction are commonly observed in VM patients. And VM patients with abnormal vestibular function have a weak effectiveness of prophylaxis medications.

\section{Abbreviations}

VM

vestibular migraine; VEMP:vestibular-evoked myogenic potentials; vHIT:video head impulse test; VNG:videonystagmography; DHI:dizziness handicap inventory

\section{Declarations}

\section{Acknowledgements}

Not applicable.

\section{Authors' contributions}

WF, JH, YB and NC designed the experiment, analyzed the data, and wrote the article. FH, DW, and YS collected data and prepared figures.YW guided the study. All authors have read and approved the final document.

\section{Funding}

Not applicable.

\section{Availability of data and materials}

The retrospective datasets are available by request from the corresponding author of this manuscript.

\section{Ethics approval and consent to participate}


All subjects provided written informed consents to participate in this study. This study was approved by the Institutional Review Board of Xijing Hospital, Fourth Military Medical University.

\section{Consent for publication}

Not applicable.

\section{Competing Interests}

The authors declare that there is no conflict of interest.

\section{References}

1. Dieterich M, Obermann M, Celebisoy N. Vestibular migraine: the most frequent entity of episodic vertigo. J Neurol. 2016;263(Suppl 1):82-9.

2. Lempert T, Olesen J, Furman J, et al. Vestibular migraine: diagnostic criteria. J Vestib Res. 2012;22(4):167-72.

3. Headache Classification Committee of the International Headache Society (IHS). The International Classification of Headache Disorders, 3rd edition (beta version). Cephalalgia. 2013; 33(9): 629-808.

4. Furman JM, Marcus DA, Balaban CD. Migrainous vertigo: development of a pathogenetic model and structured diagnostic interview. Curr Opin Neurol. 2003;16(1):5-13.

5. von Brevern $M$, Zeise $D$, Neuhauser $H$, Clarke AH, Lempert T. Acute migrainous vertigo: clinical and oculographic findings. Brain. 2005;128(Pt 2):365-74.

6. Dieterich M, Brandt T. Episodic vertigo related to migraine (90 cases): vestibular migraine. J Neurol. 1999;246(10):883-92.

7. Brandt T, Strupp M. General vestibular testing. Clin Neurophysiol. 2005;116(2):406-26.

8. Rosengren SM, Welgampola MS, Colebatch JG. Vestibular evoked myogenic potentials: past, present and future. Clin Neurophysiol. 2010;121(5):636-51.

9. Clarke AH. Laboratory testing of the vestibular system. Curr Opin Otolaryngol Head Neck Surg. 2010;18(5):425-30.

10. Fu W, Han JL, Zhao Y, Zeng LT, Weng DD. [Normal values of otolith function tests and age-related changes]. Lin Chung Er Bi Yan Hou Tou Jing Wai Ke Za Zhi. 2016;30(19):1515-20.

11. He F, Fu W, Wei D, Bai Y, Han JL. [Normal values of video-head impulse test for healthy people]. Chinese Journal of Otology. 2017;15(06):661-4.

12. Fu W, He F, Zhao R, et al. Effects of Hand Positions During Video Head-Impulse Test (vHIT) in Patients With Unilateral Vestibular Neuritis. Front Neurol. 2018;9:531.

13. Yang CJ, Lee JY, Kang BC, Lee HS, Yoo MH, Park HJ. Quantitative analysis of gains and catch-up saccades of video-head-impulse testing by age in normal subjects. Clin Otolaryngol. 2016;41(5):532-8. 
14. Shepard NT, Jacobson GP. The caloric irrigation test. Handb Clin Neurol. 2016;137:119-31.

15. Bisdorff A, Von Brevern M, Lempert T, Newman-Toker DE. Classification of vestibular symptoms: towards an international classification of vestibular disorders. J Vestib Res. 2009;19(1-2):1-13.

16. Neuhauser HK, Radtke A, von Brevern M, et al. Migrainous vertigo: prevalence and impact on quality of life. Neurology. 2006;67(6):1028-33.

17. Barbosa F, Villa TR. Vestibular migraine: diagnosis challenges and need for targeted treatment. Arq Neuropsiquiatr. 2016;74(5):416-22.

18. Stolte B, Holle D, Naegel S, Diener HC, Obermann M. Vestibular migraine. Cephalalgia. 2015;35(3):262-70.

19. Furman JM, Marcus DA, Balaban CD. Vestibular migraine: clinical aspects and pathophysiology. Lancet Neurol. 2013;12(7):706-15.

20. Radtke A, von Brevern M, Neuhauser H, Hottenrott T, Lempert T. Vestibular migraine: long-term followup of clinical symptoms and vestibulo-cochlear findings. Neurology. 2012;79(15):1607-14.

21. Radtke A, Neuhauser H, von Brevern M, Hottenrott T, Lempert T. Vestibular migraine-validity of clinical diagnostic criteria. Cephalalgia. 2011;31(8):906-13.

22. Zaleski A, Bogle J, Starling A, et al. Vestibular evoked myogenic potentials in patients with vestibular migraine. Otol Neurotol. 2015;36(2):295-302.

23. Yoo MH, Kim SH, Lee JY, Yang CJ, Lee HS, Park HJ. Results of video head impulse and caloric tests in 36 patients with vestibular migraine and 23 patients with vestibular neuritis: a preliminary report. Clin Otolaryngol. 2016;41(6):813-7.

24. Blödow A, Heinze M, Bloching MB, von Brevern M, Radtke A, Lempert T. Caloric stimulation and videohead impulse testing in Ménière's disease and vestibular migraine. Acta Otolaryngol. 2014;134(12):1239-44.

25. Power L, Shute W, McOwan B, Murray K, Szmulewicz D. Clinical characteristics and treatment choice in vestibular migraine. J Clin Neurosci. 2018;52:50-3.

26. Teggi R, Colombo B, Bernasconi L, Bellini C, Comi G, Bussi M. Migrainous vertigo: results of caloric testing and stabilometric findings. Headache. 2009;49(3):435-44.

27. Celebisoy N, Gökçay F, Sirin H, Biçak N. Migrainous vertigo: clinical, oculographic and posturographic findings. Cephalalgia. 2008;28(1):72-7.

28. Neugebauer H, Adrion C, Glaser M, Strupp M. Long-term changes of central ocular motor signs in patients with vestibular migraine. Eur Neurol. 2013;69(2):102-7.

29. Kang WS, Lee SH, Yang CJ, Ahn JH, Chung JW, Park HJ. Vestibular Function Tests for Vestibular Migraine: Clinical Implication of Video Head Impulse and Caloric Tests. Front Neurol. 2016;7:166.

30. Jung JH, Yoo MH, Song Cl, Lee JR, Park HJ. Prognostic significance of vestibulospinal abnormalities in patients with vestibular migraine. Otol Neurotol. 2015;36(2):282-8.

\section{Figures}




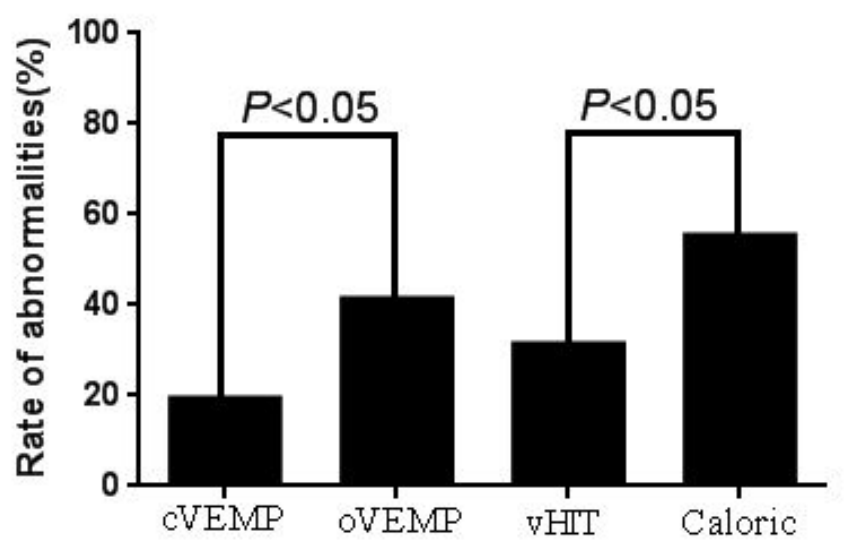

FIGURE 1|Comparison of abnormalities rate in VM patients with otolith tests(cVEMP and oVEMP) and canal tests(vHT and caloric irrigation test).

\section{Figure 1}

Comparison of abnormalities rate in VM patients with otolith tests(cVEMP and oVEMP) and canal tests(VHIT and caloric irrigation test).

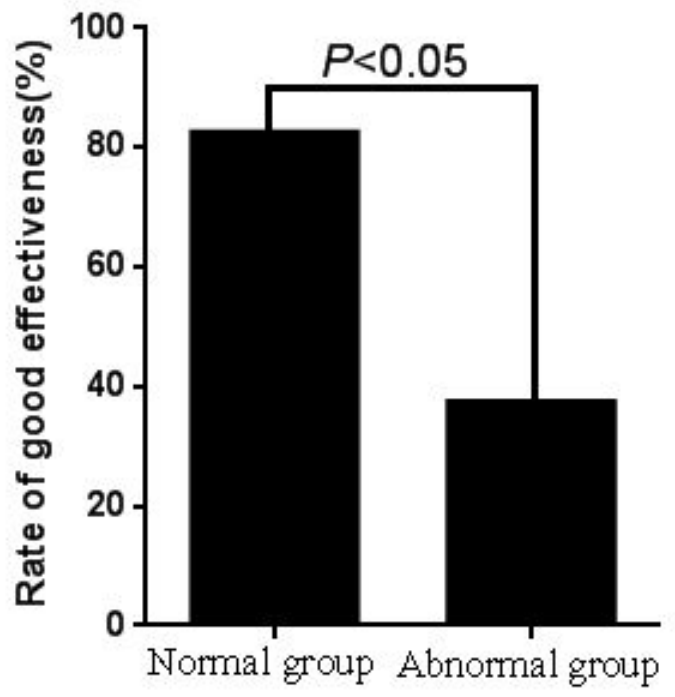

FIGURE 2|Comparison of VM patients with good effectiveness in normal vestibular test and abnormal test.

\section{Figure 2}

Comparison of VM patients with good effectiveness in normal vestibular test and abnormal test. 


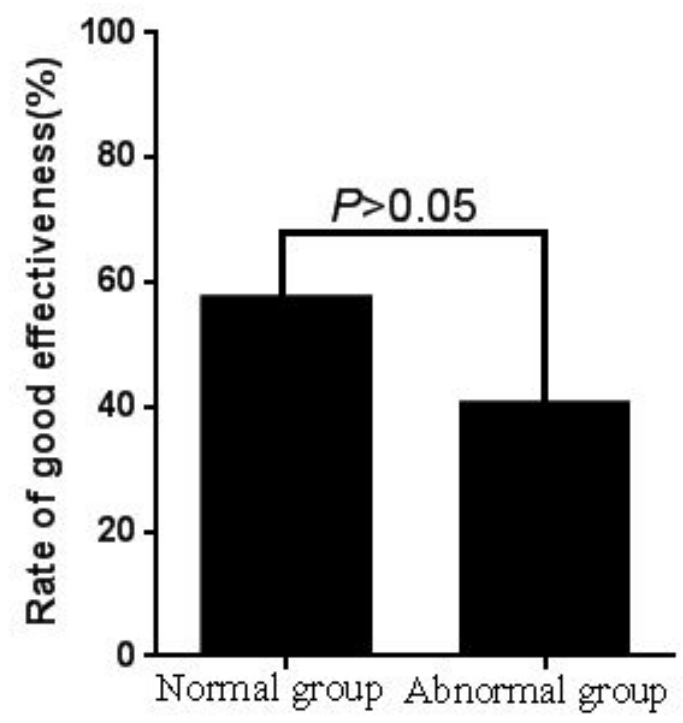

FIGURE 3|Comparison of VM patients w ith good effectiveness in normal oculomotor test and abnormal test.

\section{Figure 3}

Comparison of VM patients with good effectiveness in normal oculomotor test and abnormal test. 